\title{
BUILDING DIGITAL CAPACITY FOR HIGHER EDUCATION TEACHERS: RECOGNISING PROFESSIONAL DEVELOPMENT THROUGH A NATIONAL PEER TRIAD DIGITAL BADGE ECOSYSTEM
}

\author{
Roisin Donnelly [roisin.donnelly@teachingandlearning.ie], Terry Maguire \\ [terry.maguire@teachingandlearning.ie], National Forum for the Enhancement of Teaching and \\ Learning [www.teachingandlearning.ie], Ireland
}

\begin{abstract}
Digital Badge design and practice at a national level is a relatively new field of scrutiny and this study reports on a sector-wide initiative for building digital capacity with the design, and implementation of an ecosystem of 15 open courses in teaching and learning with digital badges to recognise the professional development of teachers in Irish higher education. Each course is provided in three delivery modes and mapped to Ireland's National Professional Development Framework for teachers. This enables multiple access points for teachers to engage in professional development via the Framework and recognize their engagement through peer triads and a digital badge ecosystem. The paper critically discusses and reflects on the study of the complex phenomena of the application of the open courses within professional contexts. A novel dimension is the implementation of a peer triad system for recognition of PD. Implementing the open courses digital badges ecosystem was challenging as this different form of assessment required a clear understanding of all stakeholder expectations, the language of recognition and how the learning outcomes could be met and validated using a peer triad assessment. This paper concludes with sectoral learning on nationally recognized open course development, including success factors for building digital capacity, challenges encountered and transferability to other contexts.
\end{abstract}

Keywords: Digital capacity; Digital badges; Peer Triads; Open Courses; Professional development; Teaching and learning

\section{Introduction}

This paper critically discusses and reflects on a national initiative on building digital capacity and professional development engagement for teaching staff across the Irish higher education sector. This took place in the Irish higher education sector during the 2017-18 academic year and was enabled through the development and recognition of an ecosystem of 15 badged professional development open courses and materials.

Within the context of a national priority in teaching and learning, a collaborative open course design initiative for all who have a teaching role in Irish higher education is presented. Building digital capacity among higher education teaching staff by enabling them to have their achievements recognized by a national credible organization ensured acceptance on the level of quality control, the actual design, and the implementation in an online learning platform. The 
collaborative approach taken in the course development teams and the perspectives that emerged from designing and delivering these open courses, along with the resulting national understanding of recognition through a digital badge ecosystem are discussed with reference to related literature.

\section{Context}

Higher education in Ireland is provided by universities (8), technological universities (1), institutes of technology (11) and some private colleges. The Higher Education Authority (HEA) is the statutory planning and development body for higher education and research in Ireland. The Authority has wide advisory powers across the third-level education sector. In addition, it is the funding authority for the universities, institutes of technology and other designated higher education institutions. The National Forum for the Enhancement of Teaching and Learning in Higher Education (National Forum) - the focus of this study - became fully operational in 2013. The role of the Forum is to enhance the teaching and learning for all students in higher education and to be an advisory body to the HEA. The National Forum is academically-led and is the key system-level "Centre of Excellence" infrastructure to support at national level, the implementation of the recommendations of the National Strategy for Higher Education to 2030 in respect of the teaching role of all the higher education institutions (HEIs). Its role is to mobilise expertise and inputs from across the entire sector and to extend and shape best practice in all HE institutions in Ireland.

The work was led by a team of representatives of the National Forum responsible for the initiative to provide national recognition for PD in Irish higher education. Specifically, the National Forum team involved the Director, the Project Manager of the professional development framework initial sectoral implementation, and the web designer. This team worked closely with 15 collaborating teams of staff from across the HE sector to design, develop and implement a series of PD openaccess courses leading to national Digital Badges that can be claimed when participants taking the open course meet identified key criteria.

A key dimension of its work was the development of a national "Professional Development Framework (PD Framework) for all those who teach in Irish Higher Education" (National Forum, 2016). The framework provides guidance for the professional development (PD) of individuals and gives direction to other stakeholders (e.g. institutions, higher education networks, educational/academic developers, policy makers and student body representatives) for planning, developing and engaging in professional development activities. Faced with the question - how best to enable all staff who teach to engage with the PD Framework - a sector-wide approach was taken to designing and implementing 15 PD open courses with digital badges to provide accessible starting points for staff to explore and engage with the PD Framework. In the context of this work, the term teach is inclusive of all the activities involved in the teaching and the facilitation of student learning, and incorporates the principles of student engagement in the learning process. The PD Framework is flexible and inclusive and can be interpreted and adapted by all teaching staff who are the audience for the open courses: academic staff across disciplines; educational/learning technologists; educational/academic developers; research staff; library staff; support staff and 
students who teach others e.g., graduate teaching assistants and those who engage in peer assisted learning.

One of the fundamental aspects of the PD Framework is its recognition of various forms of professional development. The Framework is evidence-based and was based on a sectoral review of both the accredited and non-accredited PD opportunities (programmes, modules, events, activities) that were available across the sector (National Forum, 2015). This review found that the vast majority of continuous PD opportunities were non-accredited and similar across institutions. It resulted in a national consensus being reached on the description of the different forms of PD under accredited or non-accredited categories.

The national initiative discussed in this paper describes an approach to capture the potential of structured, non-accredited PD for "recognition". In contrast to accredited provision, which has identified learning outcomes and associated ECTS or professional body endorsement, structured non-accredited PD has clear learning outcomes but does not have ECTS or endorsement from professional bodies. Non-accredited PD can be collaborative, structured or un-structured. These agreed descriptions shown in Figure 1 provide a useful structure/typology for encouraging those engaging with the PD Framework to think about the range of potential activities that constitute PD.

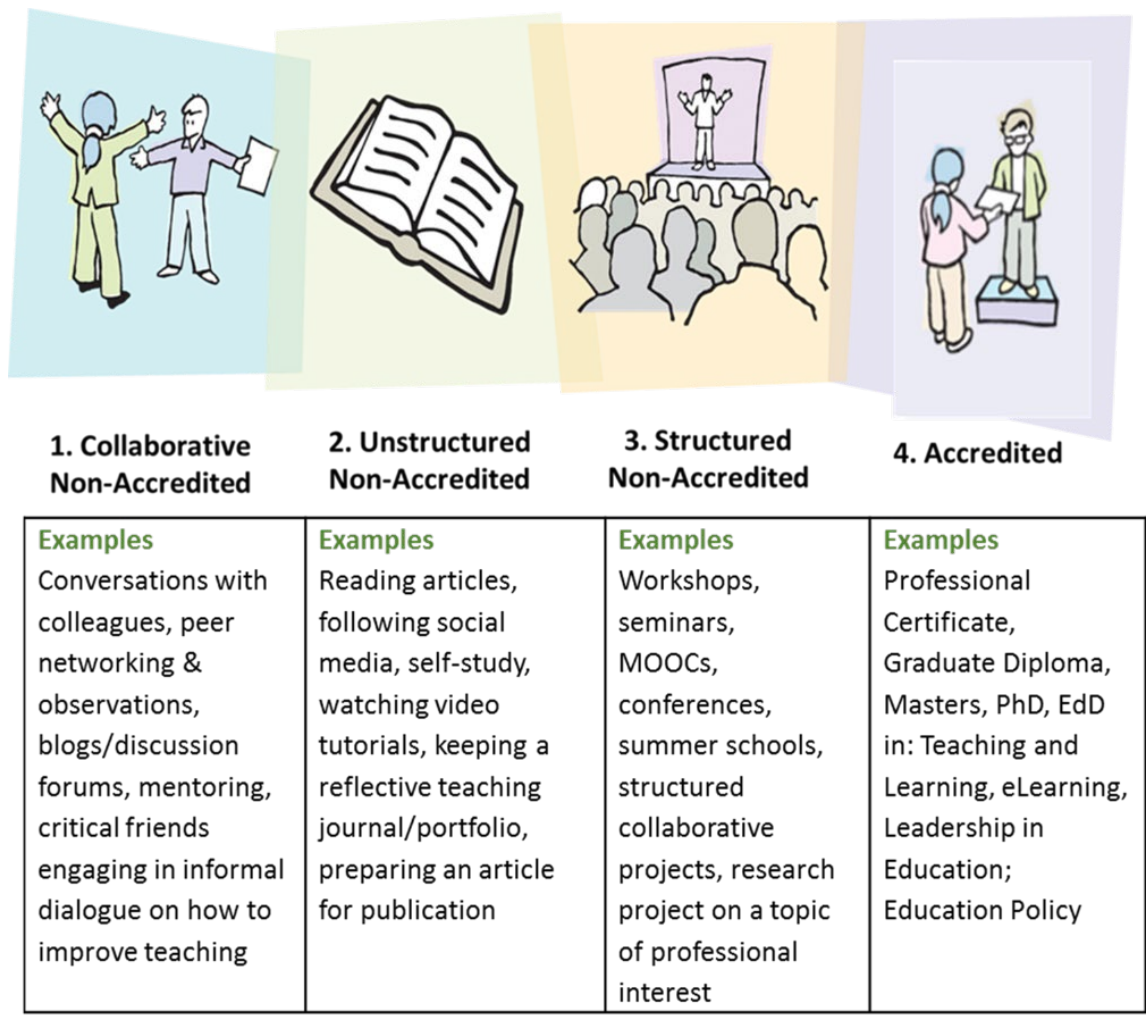

Figure 1. Typologies for engagement with Professional Development 


\section{Rationale for Professional Recognition through a Digital Badges Ecosystem}

There is now a brief examination of the nature, value, and impact of digital badges for recognition of an individual's development of knowledge and skills in teaching and learning and their potential in recognizing non-accredited learning.

Integral to the National Forum's work on PD has been to support building digital capacity across the sector. Many innovative projects were funded through Ireland's Teaching and Learning Enhancement Fund. One of these funded projects (Allaboardhe.ie) investigated the potential of micro-credentialing to recognise skill and knowledge acquisition of staff and students in $\mathrm{HE}$ (National Forum, 2017). Both staff and students responded positively to earning digital badges to recognise their achievements, and many institutions started to introduce digital badging for a range of learning activities. However, although these institutionally allocated digital badges had value within the context in which they were gained, they were not necessarily transferable to other institutional contexts, and so did not directly support staff employment mobility.

The challenge in the implementation of a national PD Framework is providing opportunities, time and space that enables all staff who teach to engage in PD. Many can be deterred by the commitment to an accredited programme because of the current demands of their work and the limited time they have available. Staff require accessible, focused PD opportunities to enable their initial engagement or their ongoing upskilling in particular approaches to teaching and learning. The series of PD open courses developed through the National Forum cover some of the most commonly delivered topics offered by HE institutions, e.g. "Getting Started with Online Teaching" or “Universal Design” (National Forum, 2015).

The open courses initiative is a means of enabling staff who teach in Irish higher education to gain recognition for their commitment to ongoing PD through the improvement of relevant skills and competencies. These digital badges were developed against nationally agreed criteria, and are recognised across the sector, thus enabling staff to have mobility within their continuous professional development journey and career advancement; therefore, it is envisioned that official recognition of skills and competencies will move with individuals as they go from one HE context to the next (Uggeri \& Barlassina, 2019).

The course developers of the open courses conceptualized the amount of learning, and assessment required for "recognition" (and gaining a nationally recognized digital badge) across three delivery modes: face-to-face/blended; self-study and online. This is in contrast to that required by existing processes and guidelines for courses leading to a European Credit Transfer System based accreditation of learning (ECTS). Building digital capacity among staff by enabling them to have their achievements recognized by a national credible organization ensured acceptance on the level of quality control, the actual design, and the implementation of the online delivery mode in a VLE.

What now follows is a backdrop summary of digital badges ecosystems, with a subsequent discussion explaining the aims of the design process for this current initiative of developing badged PD open courses. 


\section{Aims and Design of the PD Digital Badges Ecosystem}

Digital badges are evolving into a key credentialing and assessment tool for lifelong learning, which in turn is central to professionalism in many areas where it is important for academic staff to maintain their skills with continually evolving technology. A digital badge ecosystem was developed to give participants recognition for completing a PD open course and to support their future employment mobility across the HE sector. We believe digital badging can add value to professional development, and "recognition" is an important term in this national context, as there is both a concept underpinning it and a discourse around it. Anecdotally, there is considerable enthusiasm and engagement from early career colleagues for engaging with professional development (PD), but it can be less so for more established members of staff. Recognition for PD can demonstrate that an individual's commitment and achievement in teaching and learning is valued and validated, and can help develop a professional community of educators. Underpinning this work is a consideration of how we move towards a model of national PD recognition for those who engage in, and commit to, teaching and learning enhancement online in Irish higher education. A national model of recognition is a very important shift and one which will be farreaching not least because it is likely that whatever model of PD recognition is adopted will remain a feature of the sector for some time.

However, for any badging initiative to flourish, it is vital to have all of the components of a digital badge ecosystem in place. These include badge issuers, badge earners and badge consumers. Badge issuers were the National Forum who recognised the creation of the credentials to demonstrate mastery of skills and achievements. Badge earners were the individual teaching staff who want to demonstrate their achievements to various audiences in the Irish HE sector. Badge consumers are HE providers, individuals, employers, communities, and other groups that are looking for staff who possess the skills or achievements symbolized by an open courses digital badge.

The use of badging to recognise achievement is not new, with digital badges first used as a type of gamification and considered a recognition of personal achievement among computer games players. These badges are "digital tokens that appear as icons or logos awarded by institutions, organisations, groups, individuals. The badge signifies mastery of a skill or marks of experience" (Casilli \& Knight, 2012; p.1). The validity, authenticity, and value of the digital badge can be enhanced by encoding it with information about the skills it represents and the issuing organisation. In order for badges to be respected and recognised as meaningful indicators of learning, they must be linked to evidence of experiences and artefacts developed during the learning opportunity (Mayrath, 2012). Looking specifically at PD for educators, a U.S. study with school teachers by Acree (2016) found that $97 \%$ of post-course survey respondents indicated that they wanted to pursue another digital badge in the future. Similarly, a school-based study by Jones et al. (2018) on exploring teachers' perceptions and uses of digital badges received as recognition of participation in a PD programme, suggests that teachers had a favourable view of receiving digital badges and many shared their badges through digital media. A recent report (Oliver, 2019) discusses three aspects for success in implementing digital badges that have resonance for our work: building trust, adding value and achieving sustainability. 
Four key benefits to using digital badges in HE have been identified by Gibson et al. (2013): motivation, recognition, credentialing, and evidence of achievement. Motivation to acquire a badge can support individual drive to acquire further knowledge/skills. A digital badge can provide recognition of the attainment of knowledge/skills and can be structured to enable transparency in reviewing the evidence presented to support the awarding of the badge. The success or otherwise of a badge is in how it is perceived by people and institutions. This perception relies on the credibility of the issuer and the recognition of the badge by other users. Blumenstyk (2019) reports that it can be challenging to know the value of the thousands of existing credentials, much less the new ones colleges and other organizations are now starting to develop. For success in work-based learning micro-credentials, he argues that it is important to start with strong employer buy-in, because employers were instrumental in creating it. We argue that this is also the case for the nationally recognised open courses with digital badges.

Stronger connections between digital badges and other relevant innovations such as ePortfolios, and credit for prior learning, seem like promising directions for increasing the perceived value of badges (Hickey et al., 2015). However, published work has also highlighted a number of issues with the credibility of digital badges as a form of recognition on learning (Mewburn, Freund, \& Rutherford, 2014). These include concerns around quality as "everybody is offering them". This extends to digital badges being perceived as carrying more weight depending on the issuer and that the interactions around the badges are open, not proprietary. Authors have also highlighted a concern with the lack of clarity on how these smaller units of learning fit with conventional qualifications (Gallagher, 2016). Greenberg (2018) argues for the need to be transparent about what micro-credentials are and what they represent. In the context of this initiative, the badge issuer was the National Forum which provided required credibility through its endorsement. In addition, the sectoral collaborative development of the badge content ensured recognition by potential badge earners.

In the 2020 MicroHE conference, Enrenreich (2020) presents that most HE institutions are lacking practical examples of short learning courses with micro-credentials and there is a need for flexibility, personalisation and recognition. Getting institutional processes for issuing and recognising micro-credentials and using harmonised vocabularies is challenging. There are high expectations with them - contribute to better career planning, enhance student motivation and responsibility enabling more effective learning, and promote lifelong learning opportunities. Student expectations of micro-credentials is that they can offer more focused content and practical learning experiences, more current and open access knowledge and personalised learning and more flexibility in planning their studies.

Enrenreich (2020) argues that open learning recognition is not easy. There is a growing research base in Europe and a recent survey by Brown (2020) shows there is confusion in academia about what a micro-credential is, wat distinguishes it from a short course; thus they argue that it is important to be clear on definitions and language, drivers and attractors. Their research discusses a credential ecology with structured short courses and stackable and unbundled micro-credentials. 
Ralston (2020) questions the implicit assumptions that exist in a credential ecology in the academic sphere and argues for clarity on what are we unbundling, who they are for and developed for what purpose?

Remaining cognisant of such advice, this national approach to developing PD open courses with a nationally recognised digital badge aimed to:

- Provide accessible points for individuals to engage with their Professional Development Framework.

- Deliver opportunities for participants to get national recognition for their commitment to and completion of PD opportunities.

- Ensure that the provision developed mapped to the PD Framework.

- Develop a shared open-access resource for the sector.

- Distinguish between recognition of learning and formal accreditation of learning.

- Supply leadership in supporting teaching and learning enhancement in HE.

- Evolve an ecosystem for the future development of similar PD open courses.

A delineation of the process is now set out by which the PD open courses were developed, including the nature of the design teams for each course, details on how many people were involved, what roles they undertook, and how the process was managed by the National Forum. Stage 1 involved an "Expression of Interest" call being sent out to the sector, inviting submission of a proposal to develop a PD open course leading to a nationally recognised digital badge (75 applications were received). Following this, a decision was taken on which open courses were funded for development ( 15 were selected based on based on the most common themes of the non-accredited PD already available across the sector), and who the lead developer would be. Stage 2 included running an introductory workshop to bring the 15 lead developers and their 25 collaborating team members together for the first time to explore and discuss the key issues to take on board in relation to open course development and the formation of a digital badges ecosystem, and to agree an open course development plan. Stage 3 required the development of online support strategies to fit with the 4 month course development and peer review period (FAQ resources for the open courses development and designing a digital badge, best practice in webinar delivery, Guides on setting up Peer Triads and implementing and supporting them in practice, Peer Review template). These stages are discussed further in the next section.

\section{The PD Open Courses Development and Peer Triad Assessment Process}

The open courses with digital badges were developed for a national rather than an institutional context and for recognition rather than formal accreditation, and is an important initiative for Irish higher education. The courses are short ( 25 hours of learner effort), accessible (allowing participant choice across three modes: face-to-face/blended; self-study; online) and provide recognition to participants who have meet agreed criteria by awarding a National Forum digital badge. This national endorsement supports staff employment mobility by giving credibility to these badges. 
Although the course developers were selected for their expertise in the course content areas, the development process involved much more than identifying the appropriate content. The design process required a variety of issues to be discussed and negotiated including:

- What quantum of learning should be included?

- What kinds of activities should participants complete to demonstrate they have met the key criteria?

- Who would decide if the criteria had been met to enable participants to claim their digital badge?

- Who could facilitate these open courses? How would the open courses be mapped onto the national PD Framework?

In terms of design, collaborative agreement was reached that on open courses representing a specific amount of learner effort and all courses having these same components:

- Identification of four criteria that must be met to be awarded the badge;

- A short video outlining content and target audience for the open course;

- Materials and links to useful websites and resources;

- A resource package to enable others with expertise to deliver the PD open course;

- A facilitator's guide to support future delivery: the materials developed are for the use of other facilitators/trainers (including Educational Developers) to run their own open courses using these curricula, materials, and digital badges.

- The design of a series of digital badges clearly branded to the National Forum that incorporated a visual mapping of the particular course to the PD Framework.

Teams had flexibility in relation to their individual course structure, with each team agreeing the mode of delivery for which they would develop supporting materials. The fifteen open courses clustered around four themes which emerged from key areas captured in the National Forum's (2015) snapshot of accredited PD provision report (p.19): reflective practice, teaching methods, digital pedagogy, and pedagogical research skills - these formed the initial badge ecosystem.

Two of the open access PD open courses are targeted at staff beginning their professional development journey using the PD Framework as their guide (PACT and PD Reflective Practice). Lecturers new to teaching, or staff who want to develop delivery strategies in the face-to-face and online classroom, can select from a range under the Teaching Skills cluster. For more experienced teaching staff who may wish to explore professional areas of interest, Specialist Expertise, Curriculum Design, Student Focused open courses are available (Figure 2). 


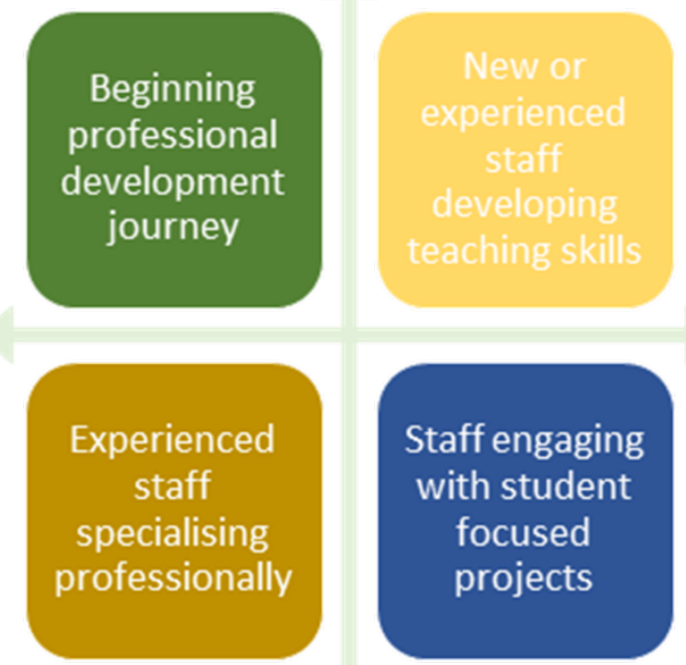

Figure 2. Badges Ecosystem: pathways for PD open-access courses

Staff who want to begin their professional development journey using the PDF as their guide are encouraged to take the following two open courses:

Table 1:

PD Reflective Practice PACT: Commitment to professional development

Reflective practice in teaching

Lecturers new to teaching or staff who want to develop their teaching skills can select from a range under the "Teaching Skills" cluster:

Table 2:

Teaching Skills

Teaching and learning strategies for new lecturers

Getting started with online teaching

Postgraduate research supervision

Mentoring essentials in teaching and learning

For more experienced teaching staff who may wish to explore professional areas of interest, an alternative pathway offers the choice of three clusters (Specialist Expertise; Curriculum Design; Student Focused):

Table 3:

\begin{tabular}{ll}
\hline Specialist Expertise & Digital policy development for T\&L \\
& Entrepreneurship education \\
& Academic writing in higher education \\
& Developing intercultural awareness \\
\hline Curriculum Design & Programme design \\
& Universal design in teaching and learning \\
& Programme-focused assessment \\
\hline Student Focused & Enabling student volunteering \\
& Student engagement \\
\hline
\end{tabular}


It was key for the National Forum that this national initiative was undertaken in collaboration with academic staff who would be the designers of the PD open courses to ensure that the sector had ownership of the courses developed, and that they could be integrated into existing institutional structures for PD. Lead developers were a mix of lecturers from particular disciplines, academic developers, and senior management; each open course development team had a lead developer and up to four collaborating partners. Collectively the teams included representatives from 20 different HE institutions. The materials developed were peer-reviewed by 30 subject experts who were not involved in the development process.

The design role involved each team working together to develop the content for the course including guidelines that would enable others to facilitate the future delivery of the course in their own institutional context. All core materials developed for each open course were then made available to download under a creative commons (open access) license from the National Forum website for use by all institutions across the sector. Currently however, National Forum endorsed badges for successfully meeting the key criteria of each open course can only be issued to staff in Irish HE.

These open course development teams were supported by the National Forum through the provision of activities (e.g. workshops, online collaborative space) that enabled developers to share their approaches, negotiate and develop a common understanding of the level, quantity of learning, and evidence of achievement required for one of these open courses. This process necessarily required that the big questions about the relationship between recognition and accreditation were considered.

As there was mixed expertise across the development teams in terms of prior knowledge and use of digital badges, the National Forum provided dedicated support to all groups to ensure everyone involved in the development process had a good understanding of open badges (https://openbadges.org), and of the technical standard (the open badge framework) which specifies which types of information is encoded within the badge.

Initial support for the course development teams provided through a badge ecosystem development workshop was acknowledged as a key initiation step for encouraging these individual academics as content experts to think about how they could work together in a genuine, informed collaboration. Research by Casilli and Hickey (2014) shows that badges work better where content and technology already exist in a field. It was important for the success of the initiative that those involved in the design process had an immediate sense of being in a learning community that together would develop something new and important for those who teach in Irish HE.

Following this face-to-face workshop at the start of the process, course development teams subsequently negotiated when, where and how often to meet, and kept the National Forum informed of their schedule. In agreement with the course development teams, a peer review process was included to bring a further layer of collaboration and discussion to the initiative. The National Forum issued a second call to the sector asking for expressions of interest in joining a peer review 
panel for this new national initiative. The Project Manager co-ordinated the selection of the peer reviewers based on their expressed expertise and interest in the topics and matched two peer reviewers to each of the open courses being developed. The two reviews of each course were completed independently. In all, the Peer Review Panel included 30 reviewers, who together played a fundamental role in the support of the course development process. As identified experts (whose professional interests and expertise aligned with the course content), each reviewer was invited to look at the content and offer constructive, supportive feedback to the development team to take on board before the course design was completed. The Peer Review Panel was key for validation in the course development process. Peer review in this context is the improvement process by which course content is evaluated for quality and significance to a field. Expert referees provided their feedback directly to the development teams. On receiving this valuable commentary, the development team had the opportunity, if required, to revise and improve their course content based on the constructive suggestions. The review had the intention of encouraging open dialogue on the course content areas between the peer reviewers and the development teams, with some identified benefits for both parties.

Designing the open course required the teams to consider how to incorporate audio, video case studies, simulations, guest speakers, role playing or exploratory prompts to enliven the PD discussions. They needed to ensure that the correct tool/media is chosen for a given PD activity and think about whether asynchronous is the right medium for a particular topic or should it be in real-time in a webinar. This involved awareness that asynchronous discussions have their own unique rhythm and opens up the need for variety in the tools used and the need for knowledge about what topics are good for brainstorming in a live webinar and what need prolonged consideration in the discussion boards e.g. an online debate. The design also involved decisions on how the course facilitators can frame the PD discussions: with current events, case studies, website reviews, journal critiques, controversial topics, reviews.

As these open courses were to be produced as a coherent ecosystem, guidelines for branding and formatting course materials, and a promotional video for each course was also provided through the National Forum. Once all open courses had been developed, a two-week series of face-to-face facilitator development workshops were delivered. This series of "train-the-trainer" workshops were run by the course developers who demonstrated how the course materials could be used and key learning points that would need to be to be negotiated. They were for people not in the development teams but rather who are facilitators for the courses that the teams have produced. As this was the first time that the particular materials and resources of the courses would be used in practice, the course developers and the National Forum agreed to consider this first version as a "beta" version with an agreement that each course would be reviewed once feedback had been gathered after the course had been run at least three times before being made available as the final version.

Peer triads were the assessment approach utilized. In the context of the open courses, a peer triad is a small group of 3 participants on the course who are encouraged to work together to share and 
discuss their approach to professional development. The National Forum facilitated a number of discussions within and between the course development teams to negotiate and agree how participants taking the course could demonstrate they had met the badge criteria. The course developers were challenged to rethink their current view of assessment, one contextualised in their institutions with the associated quality assurance processes and procedures to consider a more "appropriate and proportional" approach. This new approach needed to have rigour, be sufficient to maintain the credibility of the badges that participants would receive and at the same time, not put a huge workload on the course facilitator in terms of identifying whether the criteria had been met or not.

Through negotiation, all teams agreed that a collaborative peer triad system was rigorous enough to satisfy themselves that the criteria were met and so maintain the credibility of a National PD Digital recognition system, but at the same time "light touch" to encourage participants to claim their digital badge and for their facilitators to support this process.

To gain their digital badge, participants are required to share with their triad how they have met the four badge criteria. This is done through the opencourse.ie Moodle interface, or depending on the mode of delivery, through the national forum website or through the course Facilitator. At the beginning of each open course, it was important to make explicit the level of expected engagement generally but also specifically within the peer triads. An "Introduction to Peer Triads" guide was developed by the National Forum in collaboration with the development teams which was to be shared with the participants at the beginning of each course.

Following good practice for small groups, and to enable each triad to have rich discussions on teaching and learning - in each peer triad, it was important to have a gender balance, a mix of participants from different institutions and at different career stages, and where possible to have one participant with an interest/knowledge of learning technology, as this can be useful if the triad are using different tools to communicate.

The course development team needed to consider how to support levels of interaction in the peer triads during each course, and enable the triad to self-facilitate purposeful, meaningful and timely exchange of ideas on PD. When designing the peer triad structure, the development teams aimed to strive to develop a sense of community in the triads by encouraging participants to be both responsive and available to each other. They were encouraged to create a plan for communication in the Peer Triads, with an emphasis on communicating clearly regarding their expectations of the participants in the triad, and equally, what they participants can expect of each other in terms of response times and availability.

The triads were encouraged to pose discussable questions, problems or situations to each other and contribute intellectual content and insight to ongoing discussions. Utilising a range of questions can encourage active processing of the open course material. The continuous open nature of the Moodle VLE where the triads were established, raises questions surrounding the time investment in terms of the frequency and timing of triad interactions. When designing the 25 hours of learner 
effort for the open course, the development teams needed to think of all the elements being asked of the participant - reading each other's work and engaging in online dialogue with peers in the triad. Consideration of the climate of the triads was crucial - putting the participants at ease from the outset and understanding, appreciating and making the most of the diversity in any triad of participants from the Irish HE sector.

\section{Discussion on Collaborative Decision-Making}

The National PD open courses with digital badges ecosystem was a new, collaborative and innovative initiative for the higher education sector in Ireland. There was no template to follow and both the National Forum team and the course developers had to negotiate the way forward. Consequently, the agreement of the development process, the participant hours required and the assessment of the four key criteria identified for each open course and positioning recognition in the context of formal accredited provision raised a number of issues. The development teams were made up of the teachers and professional support staff who were experts in their subject area. While they were confident of their own knowledge and skills to develop a PD course as they had expertise relevant to the open course topic they were to design, their knowledge of digital badging was mixed; also for many, the experience of developing content for their peers to subsequently deliver was also new.

This expertise was situated in an institutional context where course development was modular, quality assured, institutional-based and a highly accountable system. When these teams are viewed as both teachers and designers, they were well equipped to bring all this expertise and know-how to the open course development process. Consequently, the initial discussions within and between the teams about the courses being developed was informed by this institutional experience, the quantum of learning related to ECTS, the triad assessment of the learning, and the QA processes.

The design teams began to tease out how the courses they were to develop could be made more accessible. They decided that a module of 5 ECTS (circa 125 hours) was too much of a commitment for many of their busy, time poor colleagues, so the courses under development would need to be shorter. Their decision was also informed by the work of the National Forum (2015) that highlighted the limited impact of very short PD opportunities (3-5 hours) on leading to a change in teaching practice. The need for participants on the open courses to have time to plan and reflect on their practice was required to support long-term positive change in their teaching. Further, the existing accredited provision available within most institutions could be taken as individual modules if any staff member wanted to commit to 125 hours of learner effort required for a 5 ECTS module. Together the development teams concluded that each open course would require 25 hours of learner effort with four clearly defined key criteria that would need be met by participants to claim the National Forum endorsed digital badge. 
Another challenge for the development teams in this process was the discussion and subsequent negotiation around how and who would determine if participants did/did not meet the key criteria. Issues raised included:

- Who was qualified to do the assessment?

- How much evidence would be required?

- How could all the incidents of the course in different institutions be moderated across all higher education institutions?

One of the pivotal discussions was concerned with the nature and type of evidence that participants would be required to provide to show that they met the key criteria to enable the digital badge to be awarded.

Through these discussions, the course development teams were in fact beginning the process of differentiating between recognition and accreditation, shown in Figure 3. They began to change their mental model of what constituted PD open courses. This model included a shift in their understanding, from their own institutional context to a national context and from the concept of accreditation to newly negotiated concept of recognition that could be facilitated by digital badges. This stage of development was very challenging for the course development teams and was strongly supported by the National Forum. A number of workshops were held which provided the opportunity for the open course development teams to discuss and negotiate the way forward. Support was provided in understanding how digital badging worked and showcasing successful national and international initiatives.

The subsequent course development also provided some challenges to the teams as they had to agree among themselves the purpose of their particular course and the main audience they were targeting. They had to agree what content to include and the recommended activities to be incorporated in its delivery to enable participants to demonstrate they had met the key criteria. In almost all cases, the peer reviewers felt that the amount of material included and the number and type of assessment activities far exceeded what could be achieved with 25 hours of learner effort. In essence, peer review comments provided further challenges to the teams in terms of the volume of content and activities. The development teams then reviewed the materials they had developed, decided what elements of the materials would remain and what could be excluded and thought about more appropriate (and less demanding) assessment activities for the peer triads.

Designing materials for other colleagues to deliver meant that the collaborating development teams had for example to reflect on why they structured and ordered their materials in a particular way; they had to ensure that the courses were suitable for use in a number of different institutions and types of institution. The development process of these PD open courses challenged individuals to think beyond their local context, to question their assumptions around how to conceptualise recognition and accreditation and the rigour, level and quantity of evidence that distinguishes recognition from formal accreditation. 


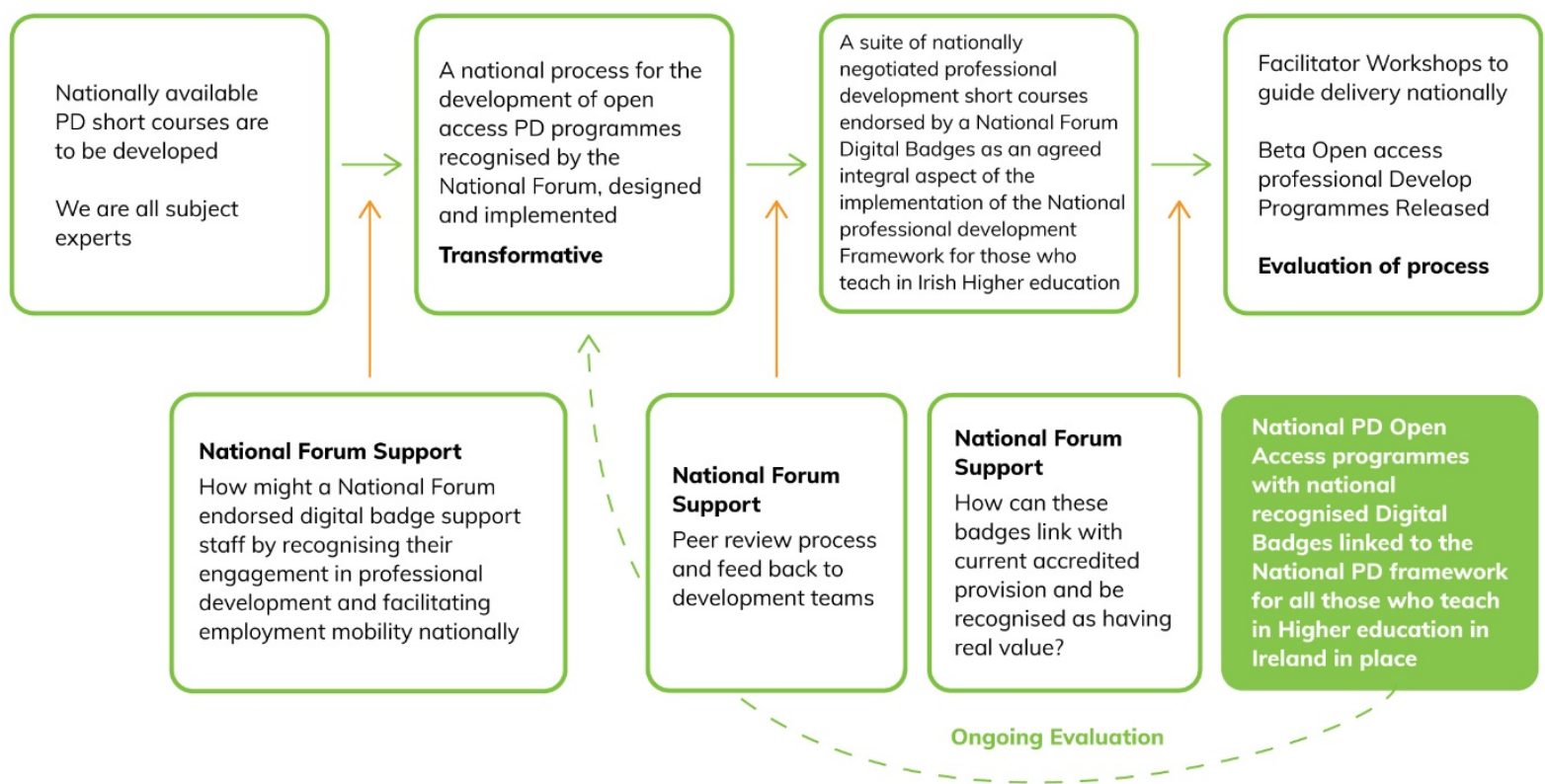

Figure 3. Nature of support for Course Development Teams

The development and subsequent roll-out of the national initiative has helped to develop the Forum's understanding of sectoral needs in relation to PD and digital badging. Each open course is clearly mapped to the national PD Framework and together these courses provide numerous access points for individuals to engage in PD aligned to personal goals. We believe as this initiative continues to roll out to the sector that it also has a wider scope in its impact i.e. to many other teachers in the T\&L community across the HE sector.

The whole process has been comprehensively negotiated. The staff involved in the design and development of a national digital badging ecosystem as a means of continuous PD were provided with the opportunity to reflect on the process and on their new learning, as well as evaluate what they have developed. Throughout the process, consideration was given to the meaning and value of recognition through a digital badge ecosystem for the open courses in the context of the national PD Framework. Through this initiative, the differentiation between recognition and accreditation at a national level has been discussed and negotiated. There is a clearer understanding of the potential role of digital badges to recognise an individual's engagement in PD. The course development teams developed an enhanced mental model for open course development in Irish higher education. The development process and the support required from the National Forum in producing these open courses is now more clearly understood.

From the experiences of the triads in action, there are a number of recommendations for their design and support. Good practice in facilitation of meaningful discussions that promote learning and build community requires careful planning, good questioning techniques and strong participant presence in each triad - all this can draw participants in and sustain lively, engaging conversations on $\mathrm{PD}$. 


\section{Conclusion}

The paper discusses and reflects on an authentic experience on the importance of provision of access to professional development through a national open courses and digital badge ecosystem for all who teach in Irish higher education. This was the first time that a national approach taken to recognizing engagement in structured non-accredited PD for the sector had been implemented with digital badges. The process of discussion, negotiation and agreement with key stakeholders in a national context on how the open courses and digital badges can be positioned with existing provision across the sector has led to Ireland having a series of nationally recognised PD opportunities available to all its higher education institutions.

This initiative was novel for everyone involved - the National Forum, the development-teams, the peer reviewers, the badge facilitators and the participants undertaking the open-access courses. Findings from Shagir's (2017) study show that collaborations are perceived as one of the important components of academic and professional development. In this National Forum initiative, all involved in the collaborative process were engaged in the steep learning curve together. In partnership, the National Forum and the course developers have designed a robust process for the development of further open, accessible, nationally recognised courses for the Irish HE sector.

From the perspective of the National Forum who led on this initiative, reflection on the process of developing open courses and agreeing standard parameters for the peer triad and digital badge ecosystem was significant. Key lessons have been learnt by the National Forum in relation to supporting engagement in PD through open courses: provision of accessibility to popular PD topics in teaching and learning; the potential of digital badges to support staff mobility by agreeing the key criteria to be met with recognized content experts in the HE sector; and on awarding a nationally endorsed digital badge for those who meet the four specified criteria. In turn, key insights offered in this paper are the transition of contributors from individual staff at institutional level to collaborating developers of PD open courses at national level. The course development teams reported the experience to be stimulating and offered them a different perspective on planning and designing open courses and materials. Insights were gained into how the development teams were collectively expert in the subject content of the open courses they were designing but had self-professed, minimal expertise of working with open badge development. Acquiring a knowledge-base in the digital badging platform in a short period of time witnessed a shift taking place in the course development teams' role - they were required to be proactive in working with their subject content and designing it in such a way that enabled the professional development of their target audience.

It was challenging to emphasise the value of recognition rather than accreditation through the whole process. This involved a change in mind-set in terms of development of the open courses and associated badges (evidenced by the early materials drafted). A new design process had to emerge to instil in staff the confidence that this was a new venture for the sector (that rigour is not lost) and they can retain flexibility to think in a different way. The Micro HE Conference (2020) presented a micro-credentials strategy for offering blended or online short learning courses and for 
recognising micro-credentials. They argue that identifying how to strike a balance between flexibility and rigidness while guaranteeing the awarded qualification meets high academic and professional standards is crucial.

A national digital badges ecosystem was new for Ireland and involved forging new pathways in terms of national recognition of PD. Confidence-building issues did not appear initially as the Course Developers were leaders in T\&L nationally. However, lessons have been learnt from the process of balancing support for content development and technical dimensions as well as alleviating any anxieties about assessment. If teachers are going into this space, they are not designing for themselves, but for other teachers to deliver the courses. We argue for a looser structure (recognition and light touch). As Pilkington (2013) has argued, the question of how experienced academics might gain recognition as professional educators without completing a course is not well explored, and this work is offered as one approach to counter this.

We need to make explicit some of the assumptions the course development teams had about delivery of the open courses and are continuing to consider ways to make this happen. We intend on continuing to building capacity with the sector with a view to growing the variety of open courses for the future and offering further fully online versions. We are considering additional ways of how best to engage the sector to undertake this. A specific challenge will be how to set up parameters to maintain quality in the open courses, despite those that may be outside institutional Quality Assurance mechanisms. We also suggest that if there is a demand within HE institutions to do so, the digital badges can be integrated into programmes within the institutions and as such must comply with assurance requirements in this regard.

There are a number of practical recommendations offered for similar initiatives with the intention of learning from our work:

- The evidence required must be an important factor in the design and structure of PD open courses. Learners should be invited to submit a wide variety of artefacts to demonstrate their knowledge and skill of their practice.

- It is important to come to terms with instructional design and thinking early about the concept of badging (particularly issues of portability and recognition).

- In the development phase of the badging ecosystem, it is important to consider how developers will engage with them (specify what them means) and make it easy to submit all of the necessary materials.

- Integrating a high level of support to the process for the collaborating development team is key, as for many of the staff this was their first experience of badging design and development for PD. For this, it is useful to plan at least one dedicated day-long badge development workshops, providing templates for designing the badge, developing resources, and access to an online collaborative platform.

- The integration of a peer review process for the validation of the course content is important, and a panel of two reviewers can give constructive feedback to each 
development team to fine-tune their work in terms of both content and navigation of online structure.

- Peer triads need careful planning for successful implementation: climate, motivation and logistics need to be considered.

Questions that will continue to be explored on recognition in this context are: What are the drivers and inhibitors of PD recognition? What are the expectations and concerns in terms of a PD recognition model? How might a national model connect with, or map to, other professional body recognition schemes, or other models of PD recognition? How might recognition align and/or complement other institutional processes and systems including recruitment, progression/promotion, staff development and PD?

\section{References}

1. Acree, L. (2016). Seven Lessons Learned from Implementing Micro-credentials. Raleigh, NC: Friday Institute for Educational Innovation at the NC State University College of Education.

2. Blumenstyk, G. (2019, May 24). Why a New Kind of 'Badge' Stands Out From the Crowd. The Chronicle of Higher Education [Blog post]. Retrieved from https://www.chronicle.com/article/Why-a-New-Kind-of-Badge$/ 246369$ ? cid $=$ wc\&source $=$ ams\&sourceId $=2352166$

3. Brown, M., (2020, July). Micro-credentials at DCU. Paper presented at the EDEN 2020 Annual Conference, Timisoara.

4. Casilli, C., \& Knight, E. (2012, June 11). 7 things to know about digital badges. Educause [Blog post]. Retrieved from https://library.educause.edu/resources/2012/6/7-things-youshould-know-about-badges

5. Enrenreich, J. (2020, July). Micro-credentials in HE. Paper presented at the EDEN 2020 Annual Conference, Timisoara.

6. Gibson, D., Ostashewski, N., Flintoff, K., Grant, S., \& Knight, E. (2013). Digital badges in education. Education and Information Technologies, 20(2), 403-410.

7. Gallagher, S. R. (2016). The Future of University Credentials: New Developments at the Intersection of Higher Education and Hiring. Cambridge, MA: Harvard Education Press.

8. Greenberg, S. (2018, April 27). Clearer Distinctions between Traditional Programs and Microcredentials will improve outcomes for both. The evoLLLution [Blog post]. Retrieved from https://evolllution.com/programming/credentials/clearer-distinctions-between-traditionalprograms-and-microcredentials-will-improve-outcomes-for-both/

9. Hickey, D., Willis, J., \& Quick, J. (2015). Where Badges Work Better. Open Badges in HE.

10. Jones, W. M., Hope, S., \& Adams, B. (2018). Teachers' perceptions of digital badges as recognition of professional development. British Journal of Educational Technology, 49(3), 427-438. 
Building Digital Capacity for Higher Education Teachers: Recognising Professional Development through a National Peer Triad Digital Badge Ecosystem

Roisin Donnelly, Terry Maguire

11. Mayrath, M. C. (2012). Technology-based Assessments for $21^{\text {st }}$ Century Skills: Theoretical and Practical Implications from Modern Research. USA: Information Age Publishing.

12. Mewburn, I., Freund, K., \& Rutherford, E. (2014). Badge trouble: piloting open badges at the Australian National University. Rhetoric and Reality: Critical Perspectives on Educational Technology ASCILITE 2014, Dunedin, New Zealand.

13. National Forum. (2015). Snapshot of Non-Accredited Continuing PD for staff who teach in Irish HE. Dublin: NF.

14. National Forum. (2016). Professional Development Framework (PD Framework) for all those who teach in Irish Higher Education. Dublin: NF.

15. National Forum. (2017). All Aboard Initiative - Digital Skills in Higher Education. Dublin: NF.

16. Oliver, B. (2019). Making micro-credentials work for learners, employers and providers. Australia: Deakin University.

17. Ralston, S. J. (2020). Higher Education's Microcredentialing Craze: a Postdigital-Deweyan Critique. Postdigital Science and Education. https://doi.org/10.1007/s42438-020-00121-8

18. Uggeri, M., \& Barlassina, L. (2019). Challenges and Opportunities of Micro-Credentials in Europe: Briefing Paper on the Award, Recognition, Portability and Accreditation of MicroCredentials. Retrieved from https://microcredentials.eu/wpcontent/uploads/sites/20/2019/12/WP3-Interviews-with-Key-Stakeholders-Decision-MakersOverall-Summary-Report.pdf 